\title{
Positional Cloning Reveals Strain-Dependent Expression of Trim 16 to Alter Susceptibility to Bleomycin-Induced Pulmonary Fibrosis in Mice
}

\author{
Anguel N. Stefanov, Jessica Fox, Christina K. Haston*
}

Meakins-Christie Laboratories and Department of Medicine, McGill University, Montreal, Canada

\begin{abstract}
Pulmonary fibrosis is a disease of significant morbidity, with no effective therapeutics and an as yet incompletely defined genetic basis. The chemotherapeutic agent bleomycin induces pulmonary fibrosis in susceptible C57BL/6J mice but not in mice of the $\mathrm{C} 3 \mathrm{H} / \mathrm{HeJ}$ strain, and this differential strain response has been used in prior studies to map bleomycin-induced pulmonary fibrosis susceptibility loci named Blmpf1 and Blmpf2. In this study we isolated the quantitative trait gene underlying Blmpf2 initially by histologically phenotyping the bleomycin-induced lung disease of sublines of congenic mice to reduce the linkage region to 13 genes. Of these genes, Trim 16 was identified to have strain-dependent expression in the lung, which we determined was due to sequence variation in the promoter. Over-expression of Trim 16 by plasmid injection increased pulmonary fibrosis, and bronchoalveolar lavage levels of both interleukin 12/23-p40 and neutrophils, in bleomycin treated $\mathrm{B} 6 . \mathrm{C} 3 \mathrm{H}-\mathrm{B} / m p f 2$ subcongenic mice compared to subcongenic mice treated with bleomycin only, which follows the $\mathrm{C} 57 \mathrm{BL} / 6 \mathrm{~J}$ versus $\mathrm{C} 3 \mathrm{H} / \mathrm{HeJ}$ strain difference in these traits. In summary we demonstrate that genetic variation in Trim 16 leads to its strain-dependent expression, which alters susceptibility to bleomycin-induced pulmonary fibrosis in mice.
\end{abstract}

Citation: Stefanov AN, Fox J, Haston CK (2013) Positional Cloning Reveals Strain-Dependent Expression of Trim16 to Alter Susceptibility to Bleomycin-Induced Pulmonary Fibrosis in Mice. PLoS Genet 9(1): e1003203. doi:10.1371/journal.pgen.1003203

Editor: Wayne N. Frankel, The Jackson Laboratory, United States of America

Received August 21, 2012; Accepted November 14, 2012; Published January 17, 2013

Copyright: (C) 2013 Stefanov et al. This is an open-access article distributed under the terms of the Creative Commons Attribution License, which permits unrestricted use, distribution, and reproduction in any medium, provided the original author and source are credited.

Funding: This work was supported by a Canadian Institutes of Health Research operating grant (MOP-62846, to CKH). The funders had no role in study design, data collection and analysis, decision to publish, or preparation of the manuscript.

Competing Interests: The authors have declared that no competing interests exist.

* E-mail: christina.haston@mcgill.ca

\section{Introduction}

The pathology of pulmonary fibrosis features excessive deposition of extracellular matrix in the lung interstitium which can occur as the result of known (environmental, therapeutic) exposures, or idiopathically, and can result in impaired lung function and, ultimately, respiratory failure. This devastating disease has an estimated annual incidence of approximately 10 cases per 100000 members of general population [1] and an associated mortality of $50 \%$ at 3 years post diagnosis [2]. The mechanisms through which pulmonary fibrosis develops are incompletely understood but likely involve dysregulated repair of alveolar epithelial cell injury [2] which may be influenced by a tissue inflammatory response $[3,4]$.

Evidence for a genetic component to pulmonary fibrosis development includes heritability of the trait in family studies [2] and recent findings from linkage and association investigations. Regarding the latter, variation in particular genes encoding ELMO domain containing 2 [5], telomerase and surfactant proteins has been associated with the trait [6], and combined investigations of linkage in affected families, and of candidate gene assessment by association and pulmonary expression, have associated variants in the mucin gene $M U C 5 B$ with pulmonary fibrosis susceptibility $[7,8]$. Only a fraction of the genetic variation which contributes to this trait has been accounted for [6], however, and given the limits of case control association studies
[9], which can include gene-environment effects, complementary investigations into the genetic basis of this disease in an animal model have been undertaken.

Investigations of mouse models wherein the fibrosis phenotype can be recapitulated in subjects controlled for age, genetic background and environmental exposure, can be completed to isolate candidate genetic variation contributing to the lung response phenotype. Specifically, the lung phenotype of C57BL/ 6J (B6) mice, following a 7day subcutaneous dose of bleomycin, consists of an alveolar inflammatory cell infiltrate with subpleural regions of fibrosis; a pathology that has been described for clinical cases of idiopathic pulmonary fibrosis [10]. This bleomycin delivery method, developed by Harrison et al. [11], and used by us $[12,13]$ has also been found to produce more fibrosis in the lung, and a fibrotic phenotype more closely resembling idiopathic pulmonary fibrosis, than the more commonly used experimental method of intratracheal drug delivery $[14,15]$. In contrast to B6, mice of the $\mathrm{C} 3 \mathrm{Hf} / \mathrm{KAM}$ or $\mathrm{C} 3 \mathrm{H} / \mathrm{HeJ}$ strains develop minimal fibrosis following bleomycin treatment $[13,16]$ and this phenotypic difference was used to map loci of bleomycin-induced pulmonary fibrosis named Blmpf1 on Chr 17 and Blmpf2 on Chr 11 [17]. From the linkage study it was established that the inheritance of B6 alleles at either of $B \operatorname{lm} p f 1$ and $B \operatorname{lmpf2}$ increased the fibrosis phenotype of $\mathrm{B} 6 \times \mathrm{C} 3 \mathrm{H}$ F2 mice. The protective influence of Chromosome $11 \mathrm{C} 3 \mathrm{H}$ alleles on the fibrosis phenotype has been confirmed as bleomycin-challenged $\mathrm{B} 6.11^{\mathrm{C} 3 \mathrm{H}}$ consomic mice were 


\section{Author Summary}

Genetic differences within the population influence an individual's susceptibility to the lung disease pulmonary fibrosis. As environmental factors also have a tremendous effect on the development of this disease, investigations in an animal model can reveal the genetic basis of this trait, under controlled circumstances. Starting from previous work that had identified a genomic region linked to fibrosis susceptibility in mice, we assayed the fibrosis response of lines of mice specifically bred to contain reduced portions of the original genetic interval, and we narrowed our study to 13 genes. Genetic evaluation pointed to the gene Trim16 as a prime candidate for affecting fibrosis, and we identified genetic variations to alter its transcription. Our functional studies showed that Trim 16 injected into the specifically bred, and bleomcyintreated, mice significantly increased their pulmonary fibrosis levels. Further evaluation of the mice showed the increase to be associated with known enhancers of fibrosis, neutrophils and interleukin $12 / 23-p 40$. This study shows that genetic variation in Trim16 affects both the lung tissue inflammatory response and the development of pulmonary fibrosis in mice and thus provides a novel pathway to fibrosis development for subsequent clinical investigation.

shown to develop significantly less pulmonary fibrosis than the levels in B6 mice [17].

Herein we generate and phenotype $B \operatorname{lmpf} 2$ congenic and subcongenic mice to show Trim16 to be the quantitative trait gene underlying $B \operatorname{lm} p f 2$.

\section{Results}

\section{Reduction of the B/mpf2 linkage region in subcongenic mice}

We initially confirmed Blmpf2 as a locus altering fibrosis susceptibility by generating and phenotyping mice in which a $29.8 \mathrm{Mb}$ fragment of Chromosome 11, encompassed by the D11Mit136 and D11Mit320 markers, from the lung fibrosisresistant $\mathrm{C} 3 \mathrm{H}$ strain, was bred onto the genetic background of lung fibrosis susceptible C57BL/6J mice, by repeated backcrossing. As shown in Figure 1, B6.Blmpf2 ${ }^{\mathrm{C} 3 \mathrm{H}}$ congenic mice (line 1) developed significantly less fibrosis $(p=0.014)$ in response to bleomycin treatment than B6 mice, but a level exceeding that of $\mathrm{C} 3 \mathrm{H} / \mathrm{HeJ}$ mice, $(\mathrm{p}=0.002)$ which is likely due to the presence of B6 alleles at the Blmpf1 locus in the congenic mice.

To narrow the Blmpf2 linkage interval and thus to reduce the number of positional candidate genes contained we created and phenotyped a panel of Blmpf2 subcongenic mice. As shown in Figure 1, mice (named B6.Blmpf $2^{\mathrm{C} 3 \mathrm{H}}$ subcongenic mice, line 6 in Figure 1) with $\mathrm{C} 3 \mathrm{H}$ alleles from, maximally, marker rs26984644 Chr11:62382506 to rs26972446 Chr11:64009126 developed the same level of pulmonary fibrosis as the congenic strain $(p=0.95)$, thus mapping the Blmpf2 fibrosis susceptibility gene to a region of $1.6 \mathrm{Mbp}$.

\section{Expression and genetic analysis of candidate genes}

The reduced 1.6 Mbp region of Blmpf2 contains 13 annotated genes (Genome Reference Consortium: GRCm38; MGI and NCBI gene annotation listed in Table S1). To assess each of the positional candidate genes as potentially contributing to the fibrosis phenotype we measured their expression levels in the lungs of both untreated $\mathrm{B} 6$ and $\mathrm{C} 3 \mathrm{H}$ mice and following exposure to bleomycin and reviewed documented strain-dependent DNA sequence variation. As shown in Figure 2 one gene, tripartite motif-containing 16 (Trim16), of strain dependent expression, was significantly increased in expression in the lungs of bleomycintreated B6 mice, compared to the levels in both untreated B6 mice and $\mathrm{C} 3 \mathrm{H}$ mice exposed to bleomycin. The gene expression levels agree with data we had previously reported from a microarray study of the $\mathrm{B} 6$ and $\mathrm{C} 3 \mathrm{H}$ response to bleomycin (GEO record GDS1492; ref 13), for the 7 linkage region genes included in the array. The expression of Cdrt4 was not detected in either strain. We also assessed the level of expression of each of the positional candidate genes, except Cdrt4, in the lungs of $\mathrm{B} 6 . B \operatorname{lm} p 2^{\mathrm{C} 3 \mathrm{H}}$ subcongenic mice (Figure S1). The majority of genes exhibited expression levels similar to those detected in the lungs from $\mathrm{C} 3 \mathrm{H}$ mice, although the expression of Tekt3 was similar to that in the lungs of B6 mice, suggesting trans regulation for this gene. Finally, the expression of Trpv2 and Z $f_{p 2} 287$ in the lung tissue from B6.Blmpf $2^{\mathrm{C} 3 \mathrm{H}}$ subcongenic mice differed from that measured in either inbred strain.

Each of the positional candidate genes was reviewed using data from the dbSNP $128 \mathrm{SNP}$ and Sanger databases to identify those genes having coding non synonymous B6/C3H SNP's as these variations could potentially contribute to the fibrosis phenotype of B6 mice and four genes (Zpp286, Zfp287, Trim16 and Fam18b) met this criterion. By in silico analysis $[18,19]$ the majority of the coding non synonymous $\mathrm{B} 6 / \mathrm{C} 3 \mathrm{H}$ variations were deemed tolerated or benign.

From the gene expression and SNP analysis, and based on data demonstrating the encoded protein to affect the secretion of cytokines of relevance of fibrosis [20], Trim16 was further investigated as a fibrosis susceptibility gene.

\section{B6/C3H sequence variation in Trim16}

Given the strain dependent expression of Trim16, we investigated the $5^{\prime}$ putative regulatory region for sequence differences which could create this differential expression. As shown in Figure 3 sequence differences in region $5^{\prime}$ to the transcription start site were documented, the majority of which verify data from the Sanger database [21]. Variations which are both evolutionarily conserved (see Figure S2) and which, based on data in PROMO, [22,23] TRANSFAC [24] and MATCH [25], potentially alter transcription factor binding sites were revealed. To test the influence of this sequence on gene transcription, we completed a promoter assay and as shown in Figure 3, the B6 allele of the region $1.3 \mathrm{kbp}$ upstream of the start site enhanced transcription relative to the $\mathrm{C} 3 \mathrm{H}$ allele.

\section{Elevated Trim 16 expression increases fibrosis in B6.Blmpf2 ${ }^{\mathrm{C} 3 \mathrm{H}}$ subcongenic mice}

To investigate whether the altered expression of Trim16 influences the fibrosis phenotype we treated $\mathrm{B} 6 . \operatorname{Blm} p f 2^{\mathrm{C} 3 \mathrm{H}}$ subcongenic mice with bleomycin and injected a plasmid of Trim16 in complex with the polyethylenimine (PEI) carrier [26,27], at day 21 after the initiation of bleomycin treatment. The expression of Trim16 in untreated subcongenic mice was similar to that of untreated $\mathrm{C} 3 \mathrm{H}$ mice, $(1.09$ relative to the $\mathrm{C} 3 \mathrm{H}$ level; $\mathrm{p}=0.78$ ) which is consistent with cis regulation. Intravenous injection of the Trim16 plasmid increased expression of Trim16 in the lungs of bleomycin-treated subcongenic mice, to B6 levels, as shown in Figure 4A.

B6.Blmpf $2^{\mathrm{C} 3 \mathrm{H}}$ subcongenic mice treated with bleomycin and the Trim16 plasmid also developed significantly increased fibrosis, assessed both histologically and with hydroxyproline measures, compared to the levels in subcongenic mice receiving bleomycin 


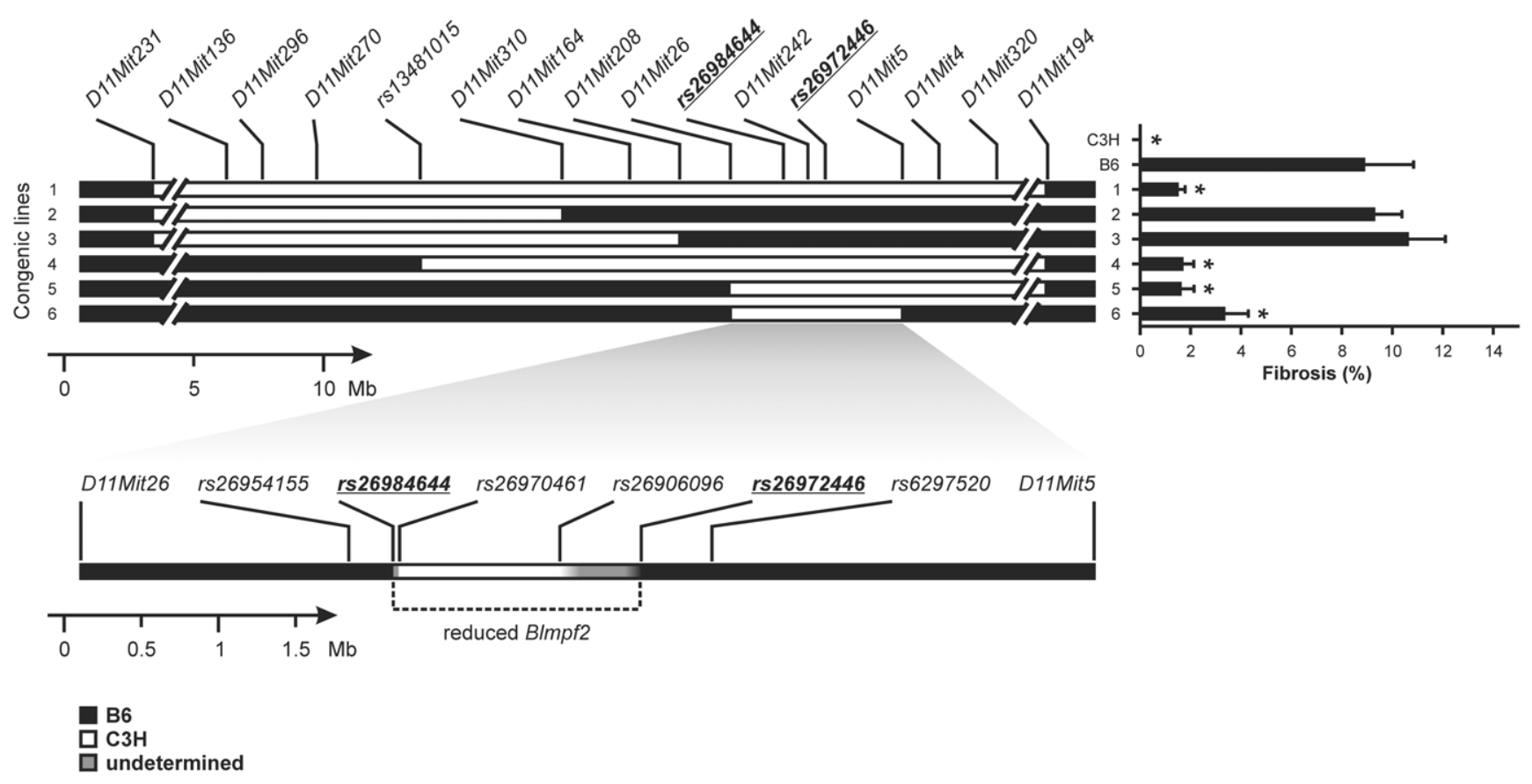

Figure 1. Bleomycin-induced lung phenotype of Blmpf2 subcongenic mice. The mice were treated with bleomycin by mini-osmotic pump and euthanized 42 days later. The percentage of the lung with fibrosis was determined from image analysis of histological sections and the mean \pm SEM of 10-19 bleomycin-treated mice for each subcongenic line, and for the parental strains, is given. ${ }^{*}$ indicates a significant difference in fibrosis from B6 mice, $p<0.05$. Genotypes [C3H alleles (white box); B6 alleles (black box)] were determined with microsatellite and SNP markers; genotypes of line 6 are expanded at the bottom of the figure.

doi:10.1371/journal.pgen.1003203.g001

alone or bleomycin and a control plasmid (Figure 4B-4D). The Trim 16 plasmid treatment resulted in $\mathrm{B} 6$. Blmpf2 ${ }^{\mathrm{C} 3 \mathrm{H}}$ subcongenic mice developing a level of fibrosis similar to that of $\mathrm{B} 6$ mice $(p=0.9)$, indicating a Trim16 deficiency to have reduced the fibrosis development in subcongenic mice.

To elucidate how the fibrosis was enhanced in Trim16 treated mice, the bronchoalveolar lavage fluid from each animal was scored for inflammatory cell types. Subcongenic mice treated with bleomycin and Trim16 plasmid presented with neutrophil levels equal to those in bleomycin treated B6 mice $(p=0.6)$ and exceeding those of subcongenic mice receiving either of bleomycin alone or bleomycin and an empty vector, and the levels in bleomycin-treated $\mathrm{C} 3 \mathrm{H}$ mice, as shown in Figure 4E.

Given that increased levels of the cytokine interleukin 12/23p40, which is involved in neutrophil recruitment [28], can cause experimental pulmonary fibrosis [29,30], we therefore assessed whether the increased fibrosis in the subcongenic mice was associated with a Trim 16 mediated enhancement of Il12/23-p40 secretion. We initially showed Il12/23-p40 levels to be relevant to fibrosis development in our model by measuring the level of this cytokine in the bronchoalveolar lavage of $\mathrm{B} 6$ and $\mathrm{C} 3 \mathrm{H}$ mice following exposure to bleomycin. As shown in Figure 4F Il-12/23$\mathrm{p} 40$ was increased to a greater extent in $\mathrm{B} 6$ than $\mathrm{C} 3 \mathrm{H}$ mice, and in Trim 16 plasmid and bleomycin treated subcongenic mice compared to subcongenic challenged with bleomycin alone, thus elevated levels of Trim 16 in the bleomycin-treated lung affect the Il12/23-p40 pathway to fibrosis.

\section{Discussion}

In previous studies the bleomycin-induced lung response of C57BL/6J mice, an established model of pulmonary fibrosis [31], was contrasted with that of $\mathrm{C} 3 \mathrm{H}$ mice and used as the base of a linkage investigation mapping susceptibility to this lung disease to two loci [17]. In this work we moved from the mapped locus to the gene by demonstrating that overexpression of Trim16 can contribute to pulmonary fibrosis development in mice.

Our approach to identify the $B \operatorname{lm} p f 2$ quantitative trait gene included experiments in congenic and subcongenic mice, with candidate gene sequence variation and expression analyses, as in other positional cloning studies [32,33]. Based on this genetic evidence the leading candidate of the genes mapping to the subcongenic interval was tripartite motif-containing 16, or Trim16, which encodes the protein Trim16. As Munding et al. [20] demonstrated that the secretion of the pro inflammatory cytokine interleukin- $1 \beta$ could be augmented in vitro by TRIM16, this gene was also a physiologically relevant candidate for fibrosis susceptibility owing to the inflammatory component of this trait.

To increase the expression of Trim16 in the lungs of B6. Blmpf $2^{\mathrm{C} 3 \mathrm{H}}$ subcongenic mice to the levels in the fibrosis prone B6 strain we made use of a plasmid transfection system which had previously been shown to produce a high level of transfected gene expression in the lung without an increase in the tissue inflammatory response $[26,27,34,35]$. With this system the elevated Trim16 expression significantly increased the pulmonary fibrosis of recipient congenic mice. Further to elevated pulmonary fibrosis the increased Trim16 expression produced higher levels of both Il12/23-p40 and neutrophils in the bronchoalveolar lavage of congenic mice. These findings are relevant as lavage neutrophilia has been associated with pulmonary fibrosis both experimentally [36], and clinically, where Kinder et al. [37] showed greater levels of neutrophils in the lavage to correlate with early mortality from pulmonary fibrosis.

Altered levels of the cytokine interleukin 12/23-p40 have also been implicated in pulmonary fibrosis pathology through studies in animal models. Specifically, Huaux et al. [29] showed the levels of 


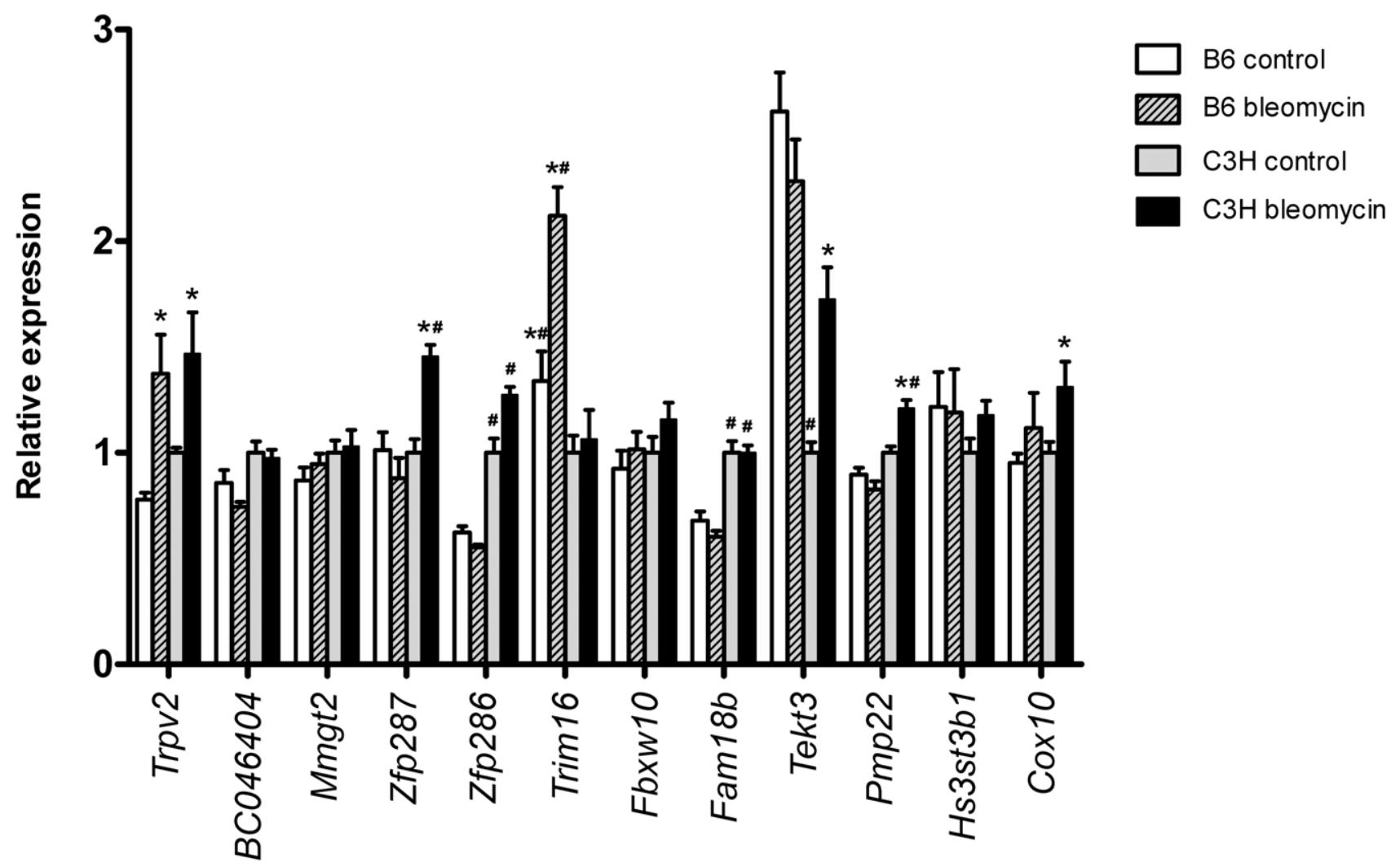

Figure 2. Pulmonary expression of reduced region $B / m p f 2$ genes. Real-time quantitative PCR of genes mapping to the reduced $B / m p f 2$ region prior to (day 0: non-treated) and following bleomycin treatment (day 42) in the lungs of B6 and C3H mice. Gene expression was normalized to the Ataxin 10 reference gene and is presented relative to the level in untreated $\mathrm{C} 3 \mathrm{H}$ mice. Mean $\pm \mathrm{SEM}$ of 5 per group. ${ }^{*}$ indicates a significant difference in expression in lungs of bleomycin-treated mice relative to untreated controls, $p<0.05$; $\#$ indicates a significant difference in expression by strain, $\mathrm{p}<0.05$.

doi:10.1371/journal.pgen.1003203.g002

interleukin 12-p40 to increase and to remain elevated in a model of experimental pulmonary fibrosis and for this cytokine subunit to decrease in abundance in resolving lung disease. In a subsequent study, Huaux et al. [30] demonstrated interleukin 12-p40 deficient mice to be protected from fibrosis development in response to challenge and, further, that supplementation with rIL-12p40 both restored the impaired pulmonary fibrotic response in these mice, and augmented the fibrosis in wild-type mice. Finally, Wilson et al. [36] reported bleomycin-induced pulmonary fibrosis and neutrophilia to be decreased in interleukin 12-p40 deficient mice.

Using a positional cloning strategy we have uncovered a novel gene of pulmonary fibrosis susceptibility in the mouse. Elevated
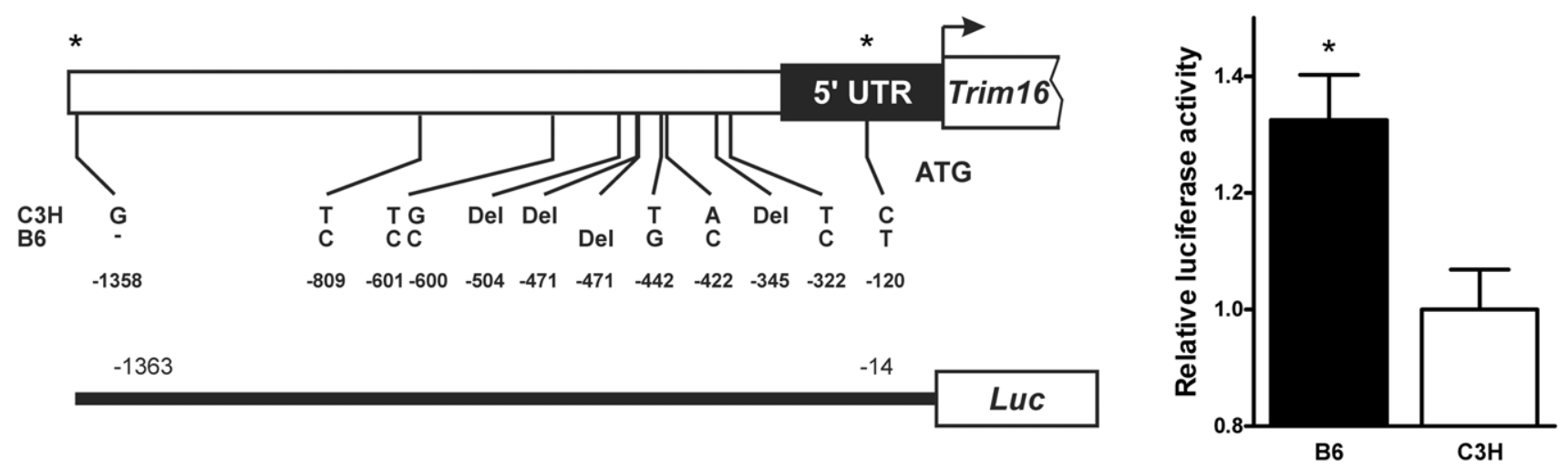

Figure 3. B6 and C3H Trim 16 promoter sequence variation alters transcription. $B 6 / C 3 \mathrm{H}$ sequence differences in the putative promoter region of Trim $16{ }^{*}$ indicates novel to Sanger, MGl). Allele specific promoter sequence alters the expression of a luciferase reporter vector transfected into the RAW 264.7 macrophage cell line.

doi:10.1371/journal.pgen.1003203.g003 
A

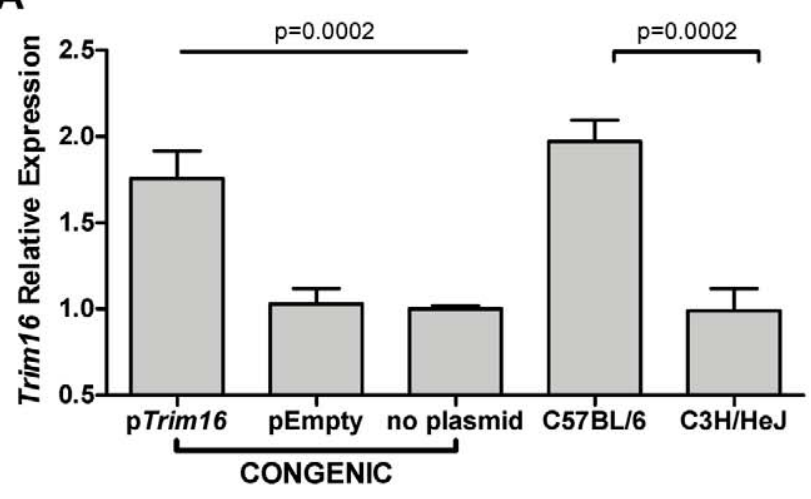

C

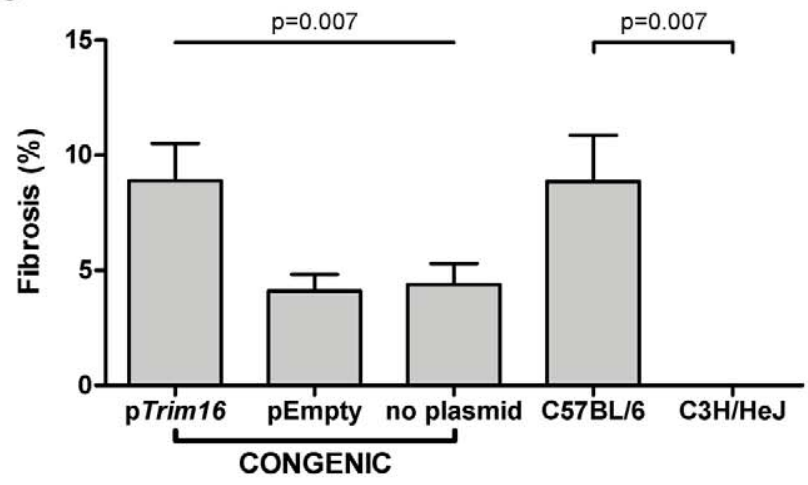

E

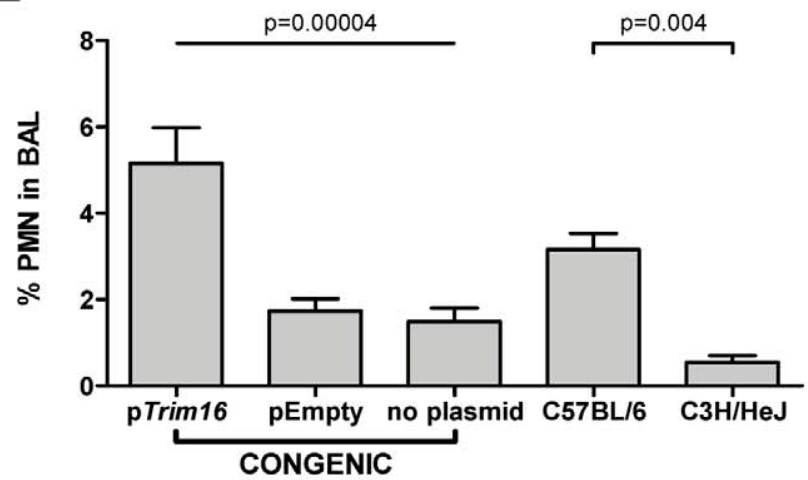

B

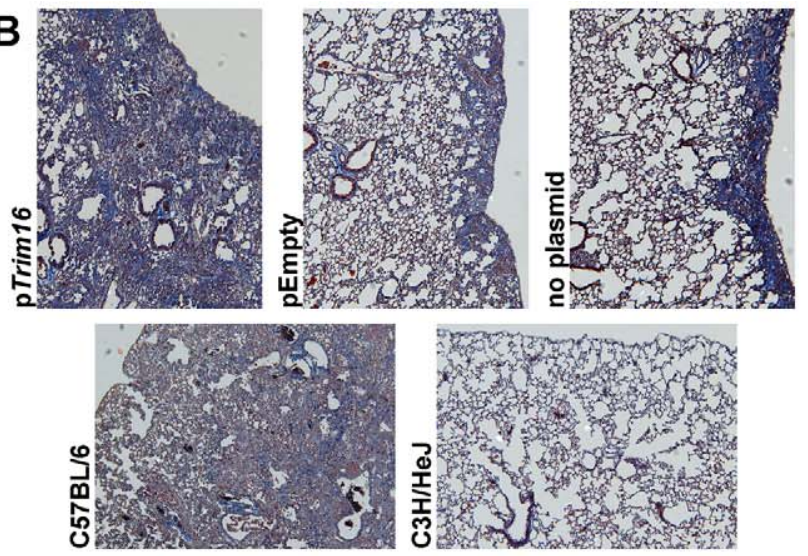

D

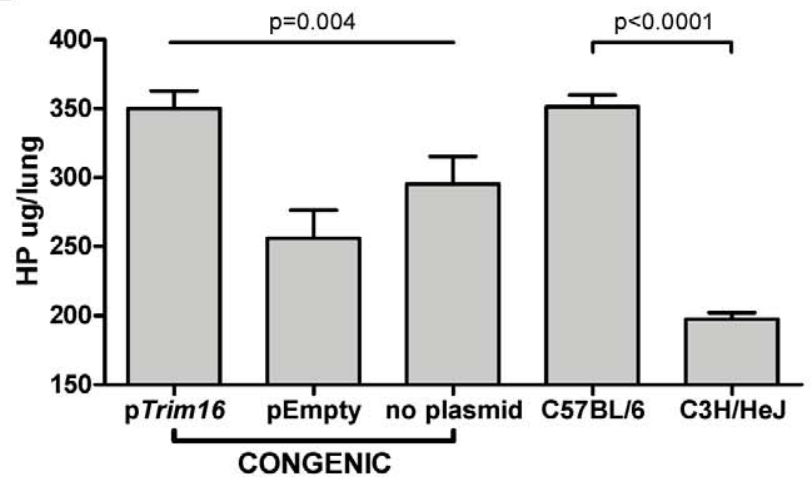

$\mathbf{F}$

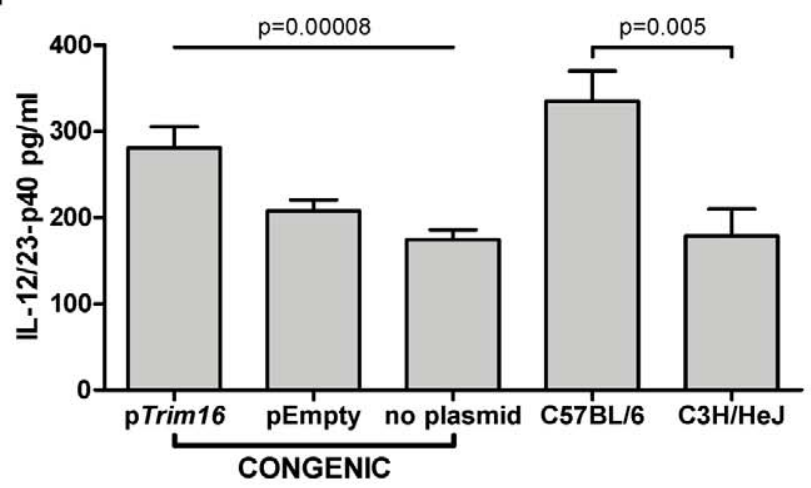

Figure 4. Trim 16 over-expression increases pulmonary fibrosis in Blmpf2 subcongenic mice. Mice were treated with bleomycin as in Figure 1 and groups of Blmpf2 subcongenic mice were treated with a Trim 16 expressing plasmid, an empty plasmid, or received no further treatment, 21 days after bleomycin treatment was initiated. The mice were euthanized at day 42 . A. Right lung Trim 16 expression, by RT-PCR; $n=4-5$ per group. B. histological sections of left lungs of congenic mice, top row and inbred strains, second row, Masson's trichrome stain, magnification of $100 \times$. C. percent fibrosis in the left lung; $n=16-19$ per group. $D$. total right lung hydroxyproline; $n=11-13$ per group. E. Bronchoalveolar lavage neutrophil counts; $n=8-13$ per group. F. Bronchoalveolar lavage supernatant interleukin-12/23p40 levels $n=8-13$ per group. The average of each phenotype \pm std. err. is given.

doi:10.1371/journal.pgen.1003203.g004

levels of this gene, Trim16, increased both the fibrosis and a specific inflammatory phenotype in mice which supports the relevance of tissue inflammation to fibrosis development in this animal model [3]. Mechanistically, although Trim16 can interact with cytokines to increase their expression [20], and a genetic deficiency of related family member Trim 21 has been shown to enhance Il12/23p-40 secretion [38], whether Triml6 directly or indirectly results in increased Il12/23-p40 remains to be determined. The finding that allele specific variation in Trim16 can affect both fibrosis susceptibility and lavage neutrophilia could have important translational implications as both the disease phenotype and a subphenotype may be plausibly evaluated for clinical association; 
which, if confirmed would reveal a specific pathway for the development of this complex disease.

\section{Materials and Methods}

\section{Ethics statement}

All animals were treated and maintained under a protocol approved by the Animal Care Committee of McGill University, in accordance with guidelines set by the Canadian Council on Animal Use and Care.

\section{Mice}

C57BL/6J and $\mathrm{C} 3 \mathrm{H} / \mathrm{HeJ}$ mice were purchased from Jackson Laboratories (Bar Harbor, ME) and housed in the Meakins Christie's animal facility. Blmpf2 congenic mice were bred by intercrossing the strains, followed by backcrossing successive generations to $\mathrm{B} 6$ mice and selecting for $\mathrm{C} 3 \mathrm{H}$ alleles in the linkage region of Chromosome 11, followed by intercrossing at the $10^{\text {th }}$ generation. To produce subcongenic mice the congenic mice were crossed to $\mathrm{B} 6$ mice, the resultant progeny were intercrossed and their offspring screened for recombination across the Blmpf2 interval using microsatellite markers. Sister/brother progeny segregating the same recombinant intervals were intercrossed to generate strains harbouring homozygous subcongenic intervals. The position of the recombinant events was subsequently refined with SNP genotyping based on the Sanger database (http://www. sanger.ac.uk/resources/mouse/genomes/) and SNP detection performed using Taqman allelic discrimination assays for SNPs rs3023266, rs 13481060 and rs6297520 and direct sequencing of amplified PCR products containing SNP sites.

\section{Pulmonary fibrosis phenotyping}

Lung damage was elicited by challenging 8 to 10 week old mice with bleomycin sulphate dissolved in sodium chloride (Mayne Pharma, Canada). The mice were treated with 100-125 units/kg of bleomycin through mini-osmotic pumps (Alzet 2001, USA) implanted subcutaneously in the mouse's back as in prior studies $[12,13]$. The pump was removed on day 8 . The mice were euthanized six weeks later, bronchoalveolar lavage was completed and the lungs were preserved for histology, hydroxyproline measures or gene expression.

For histological analysis the left lungs were perfused with 10\% neutral buffered formalin, embedded in paraffin blocks, sectioned and stained with Masson's Trichrome. The fibrosis area was quantified and compared with the surface of the entire lung to yield a percentage of fibrosis using the Image-Pro software (Media Cybernetics) as in prior studies [12,13,16]. The hydroxyproline content of the mouse lungs was determined using previously described standard methods [39]. For gene expression lung tissue was immediately homogenized in $2 \mathrm{ml}$ TRI reagent (SigmaAldrich, USA) and expression was assessed with Applied Biosystem's assays on demand as in previous studies [40,41].

\section{Bronchoalveolar lavage fluid analysis}

The lungs were lavaged with one $\mathrm{mL}$ of PBS, the lavage fluid was centrifuged ( $302 \mathrm{~g}$ for 10 minutes at $4^{\circ} \mathrm{C}$ ) and the supernatant was removed and stored at $-85^{\circ} \mathrm{C}$. The cellular pellet was resuspended in $0.25 \mathrm{~mL}$ PBS. Inflammatory cell counts were performed $(400 \times$ magnification) on cytocentrifuged cells $(214.2 \mathrm{~g}$ for three minutes), after staining with a hematoxylin-eosin kit (Hema-3 Stain Set by Protocol).

\section{Sequencing}

A 1368 bp region containing the putative Trim16 promoter from strains $\mathrm{C} 57 \mathrm{BL} / 6 \mathrm{~J}$ and $\mathrm{C} 3 \mathrm{H} / \mathrm{HeJ}$ was amplified and cloned in plasmid pJet1.2/blunt (Thermo Fisher Scientific). Inserts were sequenced and compared to the mouse genome assembly of the UCSC database (http://genome.ucsc.edu) and to that in the Sanger database to evaluate strain dependent polymorphisms.

\section{Transcription factor binding site analysis}

Putative transcription factor binding sites located within the $1.4 \mathrm{~kb}$ of the promoter region were identified in silico using the PROMO program [22,23] and TFsearch (v.1.3) of the TRANSFAC database [24] with a focus on murine specific transcription factors and transcription factor binding sites. The sequence was also analyzed with the MATCH public 1.0 algorithm by Biobase $\mathrm{GmbH}$ [24] using vertebrate weight matrices and a minimum false negative profile.

In order to determine evolutionary conservation of promoter region B6/C3H SNPs or deletions we used the Multiz Alignment \& Conservation algorithm of the UCSC genome browser (http:// genome.ucsc.edu; [42]). The graphic output was created using CodonCode Aligner (v. 3.7.1, Codon Code Corporation).

\section{Promoter cloning and transcription assay}

A $1368 \mathrm{bp}$ fragment $(-1372$ to $-4 \mathrm{bp})$ was amplified from strains $\mathrm{C} 57 \mathrm{BL} / 6 \mathrm{~J}$ and $\mathrm{C} 3 \mathrm{H} / \mathrm{HeJ}$ by $\mathrm{PCR}$ and cloned into the KpnI/HindIII sites of vector pGL3-Basic (Promega, Madison, WI). Sequencing of the inserts was completed to confirm allelic specificity. RAW246.7 macrophage cells were co-transfected with the reporter vector, or empty pGL3-basic, and pRL-SV40 (Promega), which was used as an internal control for transfection efficiency. Twenty four hours after transfection, cells were assayed for both firefly and renilla luciferase activity using the DualLuciferase Reporter Assay System (Promega, Madison, WI).

\section{Plasmid delivery to mouse lung}

A plasmid of the full length $\mathrm{B} 6$ mouse Trim $16 \mathrm{cDNA}$ with the 252 bp 5' UTR and 3' UTR (accession NM_053169), cloned into the EcoRI - NotI sites of expression vector pDream2.1/MCS, and an empty modified pDream2.1/MCS vector, were obtained from Genscript (GenScript, USA). Prior to cloning the vector was modified by removing an $18 \mathrm{nt}$ Flag tag sequence to avoid possible interference with the expressed protein structure. Plasmid insert specificity and orientation were confirmed by sequencing. The cationic linear polyethylenimine in vivo-jetPEI (Polyplus-transfection, France; MJS Biolynx, Canada) was used for plasmid transfection to the mouse lung according to the manufacturer's instructions. The PEI $(6.5 \mu \mathrm{l})$ and Trim 16 plasmid $(40 \mu \mathrm{g})$ complex was resuspended in a sterile $5 \%$ glucose solution $(400 \mathrm{uL}$ total $)$ and injected into the tail vein of mice.

\section{ELISA}

The level of Il-12/23-p40 in the bronchoalveolar lavage supernatant was assayed with a murine Il-12/23(p40) ELISA kit (eBioscience, USA) according to the manufacturer's instructions.

\section{Statistics}

Phenotypic differences between groups were assessed with Student's t test and among groups of congenic mice receiving distinct treatments, as in Figure 4, by an analysis of variance followed by Tukey post hoc tests. 


\section{Supporting Information}

Figure S1 Pulmonary expression of reduced region Blmpf2 genes in Blmpf2 subcongenic mice. Real-time quantitative PCR of genes mapping to the reduced $B l m p f 2$ region prior to (day 0: non-treated) and following bleomycin treatment (day 42) in the lungs of Blmpf2 subcongenic mice, relative to that of the parental $\mathrm{B} 6$ and $\mathrm{C} 3 \mathrm{H}$ mice. Gene expression was normalized to the Ataxin 10 reference gene and is presented relative to the level in untreated $\mathrm{C} 3 \mathrm{H}$ mice. Mean \pm SEM of 5 per group. * indicates a significant difference in expression in lungs of bleomycin-treated mice relative to untreated controls, $\mathrm{p}<0.05$; \# indicates a significant difference in expression to $\mathrm{B} 6$ mice, $\mathrm{p}<0.05$.

(TIF)

Figure $\mathbf{S} 2 \mathrm{~B} 6 / \mathrm{C} 3 \mathrm{H}$ variation in Trim 16 promoter sequence is evolutionarily conserved. The Multiz Alignment \& Conservation

\section{References}

1. Raghu G, Collard HR, Egan JJ, Martinez FJ, Behr J, et al. (2011) An official ATS/ERS/JRS/ALAT statement: idiopathic pulmonary fibrosis: evidencebased guidelines for diagnosis and management. Am J Respir Crit Care Med 183:788-824.

2. King TE Jr, Pardo A, Selman M. (2011) Idiopathic pulmonary fibrosis. Lancet 378:1949-61.

3. Wynn TA. (2011) Integrating mechanisms of pulmonary fibrosis. J Exp Med 208:1339-50.

4. Nuovo GJ, Hagood JS, Magro CM, Chin N, Kapil R, et al. (2012) The distribution of immunomodulatory cells in the lungs of patients with idiopathic pulmonary fibrosis. Mod Pathol 25:416-33.

5. Hodgson U, Pulkkinen V, Dixon M, Peyrard-Janvid M, Rehn M, et al.(2006) ELMOD2 is a candidate gene for familial idiopathic pulmonary fibrosis. Am J Hum Genet 79:149-54.

6. Garcia CK. (2011) Idiopathic pulmonary fibrosis: update on genetic discoveries. Proc Am Thorac Soc 8:158-62.

7. Seibold MA, Wise AL, Speer MC, Steele MP, Brown KK, et al. (2011) A common MUC5B promoter polymorphism and pulmonary fibrosis. N EnglJ Med 364:1503-12.

8. Zhang Y, Noth I, Garcia JG, Kaminski N. (2011) A variant in the promoter of MUC5B and idiopathic pulmonary fibrosis. N Engl J Med 364:1576-7.

9. Todd JL, Goldstein DB, Ge D, Christie J, Palmer SM. (2011) The State of Genome-Wide Association Studies in Pulmonary Disease: A New Perspective. Am J Respir Crit Care Med 184:873-80.

10. Gross TJ, Hunninghake GW. (2001) Idiopathic pulmonary fibrosis. N EnglJ Med 345:517-25.

11. Harrison JH Jr, Lazo JS. (1987) High dose continuous infusion of bleomycin in mice: a new model for drug-induced pulmonary fibrosis. J Pharmacol Exp Ther 243:1185-94.

12. Lemay AM and Haston CK. (2005) Bleomycin-induced pulmonary fibrosis susceptibility genes in $\mathrm{AcB} / \mathrm{BcA}$ recombinant congenic mice. Physiol Genomics 23:54-61.

13. Haston CK, Tomko TG, Godin N, Kerckhoff L, and Hallett MT. (2005) Murine candidate bleomycin induced pulmonary fibrosis susceptibility genes identified by gene expression and sequence analysis of linkage regions. J Med Genet 42:464-473

14. Gabazza EC, Taguchi O, Adachi Y. (2002) Bleomycin-induced lung fibrosis: the authors should have used another method to induce pulmonary lesions resembling human idiopathic pulmonary fibrosis. Am J Respir Crit Care Med 165:845-6

15. Aono Y, Ledford JG, Mukherjee S, Ogawa H, Nishioka Y, et al. (2012) Surfactant protein-D regulates effector cell function and fibrotic lung remodeling in response to bleomycin injury. Am J Respir Crit Care Med 185:525-36.

16. Haston CK, Amos CI, King TM, Travis EL. (1996) Inheritance of susceptibility to bleomycin-induced pulmonary fibrosis in the mouse. Cancer Res 56:2596-601.

17. Haston CK, Wang M, Dejournett RE, Zhou X, Ni D, et al. (2002) Bleomycin hydrolase and a genetic locus within the $\mathrm{MHC}$ affect risk for pulmonary fibrosis in mice. Hum Mol Genet 11:1855-63.

18. Kumar P, Henikoff S, Ng PC. (2009) Predicting the effects of coding nonsynonymous variants on protein function using the SIFT algorithm. Nat Protoc 4:1073-81.

19. Adzhubei IA, Schmidt S, Peshkin L, Ramensky VE, Gerasimova A, et al.(2010) A method and server for predicting damaging missense mutations. Nat Methods 7:248-9.

20. Munding C, Keller M, Niklaus G, Papin S, Tschopp J, et al. (2006) The estrogen-responsive $\mathrm{B}$ box protein: a novel enhancer of interleukin-lbeta secretion. Cell Death Differ 13:1938-49. algorithm was used to evaluate evolutionary conservation of polymorphisms within the 1368 bp region upstream Trim16 ATG. Four polymorphisms were found to have different degrees of conservation among the species. A. SNP rs26955306 at position -422 ; B. deletion between SNP -422 and -322 ; C. SNP rs49831756 at position -322 and D. novel SNP at position -120 . (TIF)

Table S1 NGBI and MGI identifiers of genes and loci described in this study.

(DOC)

\section{Author Contributions}

Conceived and designed the experiments: CKH ANS. Performed the experiments: ANS JF. Analyzed the data: ANS CKH. Wrote the paper: CKH.

21. Keane TM, Goodstadt L, Danecek P, White MA, Wong K, et al. (2011) Mouse genomic variation and its effect on phenotypes and gene regulation. Nature 477:289-94.

22. Messeguer X, Escudero R, Farré D, Núñez O, Martínez J, et al. (2002) PROMO: detection of known transcription regulatory elements using speciestailored searches. Bioinformatics 18:333-4.

23. Farré D, Roset R, Huerta M, Adsuara JE, Roselló L, et al. (2003) Identification of patterns in biological sequences at the ALGGEN server: PROMO and MALGEN. Nucleic Acids Res 31:3651-3.

24. Heinemeyer T, Wingender E, Reuter I, Hermjakob H, Kel AE, et al. (1998) Databases on transcriptional regulation: TRANSFAC, TRRD and COMPEL. Nucleic Acids Res 26:362-7.

25. Kel AE, Gössling E, Reuter I, Cheremushkin E, Kel-Margoulis OV, et al. (2003) MATCH: A tool for searching transcription factor binding sites in DNA sequences. Nucleic Acids Res 31:3576-9.

26. Goula D, Benoist C, Mantero S, Merlo G, Levi G, et al. (1998) Polyethylenimine-based intravenous delivery of transgenes to mouse lung. Gene Ther 5:1291-5.

27. Goula D, Becker N, Lemkine GF, Normandie P, Rodrigues J, et al.(2000) Rapid crossing of the pulmonary endothelial barrier by polyethylenimine/DNA complexes. Gene Ther 7:499-504.

28. Smith E, Zarbock A, Stark MA, Burcin TL, Bruce AC, et al.(2007) IL-23 is required for neutrophil homeostasis in normal and neutrophilic mice. J Immunol 179:8274-9.

29. Huaux F, Lardot C, Arras M, Delos M, Many MC, et al. (1999) Lung fibrosis induced by silica particles in NMRI mice is associated with an upregulation of the p40 subunit of interleukin-12 and Th-2 manifestations. Am J Respir Cell Mol Biol 20:561-72.

30. Huaux F, Arras M, Tomasi D, Barbarin V, Delos M, et al. (2002) A profibrotic function of IL-12p40 in experimental pulmonary fibrosis. J Immunol 169:265361.

31. Mouratis MA, Aidinis V. (2011) Modeling pulmonary fibrosis with bleomycin. Curr Opin Pulm Med 17:355-61.

32. Tomida S, Mamiya T, Sakamaki H, Miura M, Aosaki T, et al. (2009) Usp46 is a quantitative trait gene regulating mouse immobile behavior in the tail suspension and forced swimming tests. Nat Genet ;41:688-95.

33. Bhatnagar S, Oler AT, Rabaglia ME, Stapleton DS, Schueler KL, et al.(2011) Positional cloning of a type 2 diabetes quantitative trait locus; tomosyn-2, a negative regulator of insulin secretion. PLoS Genet 10: e1002323. doi:10.1371/ journal.pgen.1002323

34. Oh YK, Kim JP, Yoon H, Kim JM, Yang JS, et al. (2001) Prolonged organ retention and safety of plasmid DNA administered in polyethylenimine complexes. Gene Ther 8:1587-92.

35. Bonnet ME, Erbacher P, Bolcato-Bellemin AL. (2008) Systemic delivery of DNA or siRNA mediated by linear polyethylenimine (L-PEI) does not induce an inflammatory response. Pharm Res 25:2972-82.

36. Wilson MS, Madala SK, Ramalingam TR, Gochuico BR, Rosas IO, et al. (2010) Bleomycin and IL-1beta-mediated pulmonary fibrosis is IL-17A dependent. J Exp Med 207:535-52.

37. Kinder BW, Brown KK, Schwarz MI, Ix JH, Kervitsky A, et al. (2008) Baseline BAL neutrophilia predicts early mortality in idiopathic pulmonary fibrosis. Chest 133:226-32.

38. Espinosa A, Dardalhon V, Brauner S, Ambrosi A, Higgs R, et al. (2009) Loss of the lupus autoantigen Ro52/Trim21 induces tissue inflammation and systemic autoimmunity by disregulating the IL-23-Th17 pathway. J Exp Med 206:166171

39. Edwards CA, O'Brien, Jr. WD. (1980). "Modified assay for determination of hydroxyproline in a tissue hydrolyzate." Clin Chim Acta 104:161-167. 
40. Paun A, Fox J, Balloy V, Chignard M, Qureshi ST, et al. (2010) Combined Tlr2 and Tlr4 deficiency increases radiation-induced pulmonary fibrosis in mice. Int J Radiat Oncol Biol Phys 77:1198-205.

41. Thomas DM, Fox J, Haston CK. (2010) Imatinib therapy reduces radiationinduced pulmonary mast cell influx and delays lung disease in the mouse. Int J Radiat Biol 86:436-44.
42. Blanchette M, Kent WJ, Riemer C, Elnitski L, Smit AF, et al. (2004) Aligning multiple genomic sequences with the threaded blockset aligner. Genome Res 14:708-15. 